\title{
СУВЕРЕННОСТЬ ПСИХОЛОГИЧЕСКОГО ПРОСТРАНСТВА ЛИЧНОСТИ В ПОЛУЗАКРЫТОЙ УЧЕБНОЙ ГРУППЕ: ЛИЧНОСТНЫЕ И ГРУППОВЫЕ ФАКТОРЫ
}

Работа подготовлена в рамках Государственного задания № 0138-20210010 «Социально-психологические факторы поведения личности и группы в условиях глобальных изменений» Тарасов С.В., Дробышева Т.В. (Институт Психологии РАН, Москва, Россия) sementarasovvas@gmail.com,tdrobysheva@mail.ru

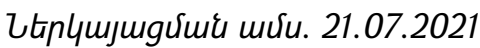
9pupunuर्ume uर्जu. 23.08.2021

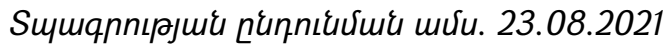

В исследовании рассматривается вопрос о сохранении психологической приватности личности в условиях полузакрытой группы как показателе ее субъектных качеств. Целью исследования стало выявление вклада социально-психологических характеристик (личностных и групповых) в регрессионную модель суверенности психологического пространства в группе курсантов военного вуза. Результаты показали, что суверенность психологического пространства обусловлена больше социально-психологическими (ценностные ориентации, мотив поступления и выбора профессии в будущем, представления о своей группе), чем групповыми (групповая сплоченность, социометрический статус, групповые нормы) характеристиками.

Ключевые слова: суверенность психологического пространства личности, учебная группа полузакрытого типа, соотношение индивидуального и коллективного субъекта, специфика сочиализации.

DOI: https://doi.org/10.46991/SBMP/2021.4.2.334

Проблематика полузакрытых учебных групп представляет интерес для узкого круга специалистов по разным причинам. В первую очередь, в связи с недостаточной разработанностью критериев, признаков и свойств объекта исследования -полузакрытой группы, во-вторую - по причине ограниченности доступа для проведения исследования. В случае с учебными группами это вызвано закрытостью самих образовательных учреждений, ориентированных на профессиональную подготовку будущих военных, спортсменов, священников, и т.п. Полузакрытый характер таких групп определяется по критерию свободного входа в группу (механизм - привлекательность целей и задач групповой деятельности) и ограниченности выхода из нее [5, и др.]. 
Организационно-образовательная среда в данных учреждениях регулируется предписаниями и правилами Устава, жестко регулирующими поведение всех участников учебного процесса, что положительно влияет на субъектные качества группы - ее сплоченность, взаимозависимость, самостоятельность, совместимость, и т.п. [1, и др.]. Особенно, если речь идет об образовательных (средних и высших) учреждениях военного профиля подготовки, содержание которой отличается направленностью на профессиональную подготовку, патриотическое воспитание, углубленное изучение общеобразовательных предметов, высокую досуговую активность. В то же время организационнопространственная среда образовательного учреждения такого типа существенно ограничивает психологическую приватность личности членов группы, так как определяется интернатным или полуинтернатным проживанием, характеризующимся нарушением границ фризического и психологического пространства личности. Данное противоречие ставит под сомнение факт субъектности группы и актуализирует научную проблему исследования о соотношении индивидуального и группового при рассмотрении учебной группы как коллективного субъекта [9 и др.].

По мнению С.К. Нартовой-Бочавер, суверенность психологического пространства (СПП) обеспечивает личности чувство безопасности, как фризической, так и психологической. Позитивно сорормированное свойство выступает некоторым ориентиром для понимания других людей и выстраивания отношений с ними и обществом в целом, в то время как депривированность суверенности личности приводит к ее маргинализации, выраженной в агрессивном отношении к социуму и самой себе [3]. Все вышеизложенное указывает на важность сохранения психологической приватности личности в процессе ее социализации. В частности, в наших ранних исследованиях были обнаружены некоторые социально- психологические эффректы обучения в условиях кадетского корпуса при их сопоставлении со школой. Обнаружили: направленность группы на активную самореализацию; выраженность упрямства и своеволия членов группы в отстаивании своих интересов; отсутствие в структуре группы категории изолированных членов; ориентацию членов группы на ценность уверенности в себе и познания $[2,6]$.

По сравнению с подростками -учащимися средних общеобразовательных учреждений полузакрытого типа, юноши - студенты военного вуза, отличаются более выраженной психологической приватностью личности. Однако условия их организационной среды - круглосуточное нахождение на территории учреждения, проживание в казарме/общежитии, строгий распорядок дня, половая гомогенность среды, высокий внешний контроль за жизнедеятельностью личности в группе и др., по-нашему мнению, снижают показатели 
суверенности психологического пространства учащихся. В частности, суверенность физического тела, территории, личных вещей и привычек. В таком случае актуальным становится изучение личностных и групповых фракторов социально-психологических характеристиках учащихся военного вуза, как ресурсов сохранения их психологической приватности в специфичных условиях жизнедеятельности полузакрытой группы.

Опираясь на вышеизложенное, сфрормулировали цель и гипотезу исследования.

Цель исследования - выявить и проанализировать социально-психологические и групповые факторы суверенности психологического пространства личности в учебной группе полузакрытого типа.

Гипотезами исследования являются предположения: 1) выраженность суверенности психологического пространства личности в учебной группе полузакрытого типа обусловлена как социально-психологическими, так и групповыми характеристиками, выступающими в роли «внешних» и "внутренних» фракторов; 2) частные аспекты суверенности психологического пространства в большей степени связаны с социально-психологическими (личностными), чем с групповыми характеристиками; 3) вклад социальнопсихологических (личностных) и групповых характеристик респондентов как предикторов показателя суверенности различается. Вклад групповых характеристик меньше, чем социально-психологических.

Объектом исследования выступили учебные группы полузакрытого типа. Предмет исследования: связь между выраженностью суверенности психологического пространства личности и социально-психологическими характеристиками учащихся в учебных группах полузакрытого типа.

Методы исследования. Выборка была представлена курсантами первого курса военного вуза, четыре учебных группы полузакрытого типа. Общий объем выборки: 115 человек в возрасте 18-20 лет, преимущественно юноши (84\%). Асимметрия по полу объясняется спецификой полузакрытых учебных групп и военной специализацией вуза.

Программа исследования была составлена в соответствии с целью исследования и сорормулированными гипотезами. В работе применяли методику «Суверенность психологического пространства - 2010» С.К. Нартовой-Бочавер [4]. Она включает общую шкалу суверенности психологического пространства и шесть субшкал: суверенность фризического тела, суверенность территории, суверенность вещей, суверенность привычек, суверенность социальных связей и суверенность ценностей.

В изучении социально-психологических характеристик личности использовали: методику ценностных ориентаций Е.Б. Фанталовой [7]; авторский опросник, ориентированный на выявление: мотивации поступления 
в военный вуз, профессиональной ориентации (представления о будущей профессии), субъективной оценки важности, значимости показателей успешности в жизни. С целью изучения представлений личности о группе применяли ассоциативный тест. Обработку полученных результатов осуществляли с помощью контент-анализа. Разработанная нами матрица включала пятнадцать категорий анализа: представления о группе как коллективе, о группе друзей, товарищей, конкретной учебной группе; представления о межличностных и деловых отношениях, о досуге в группе; представления, раскрывающие характер внутригрупповых отношений (помогающие, поддерживающие и т.п.).

С целью выявления групповых характеристик применяли метод социометрии с критериями межличностного и делового взаимодействия. Для анализа уровня групповой сплоченности использовали индекс групповой сплоченности Сишора [8]. Авторский опросник, направленный на выявление отношения группы к нормам и правилам образовательной среды, включал пять вопросов, ориентированных на субъективную оценку (степень согласия/несогласия по 5балльной шкале Лайкерта) норм и правил организационно-образовательной среды вуза. Оценка группового отношения производилась путем подсчета среднего значения в каждой группе.

Применялись следующие методы статистического анализа: частотный анализ, проверка нормальности распределения по критерию КолмогороваСмирнова. Для выявления различий применяли непараметрический критерий Н Краскала-Уоллиса для k выборок. Регрессионный анализ применялся с целью выявления предикторов суверенности психологического пространства в группах полузакрытого типа.

Результаты и обсуждение результатов исследования. На первом этапе был проведен сравнительный анализ социально-психологических портретов четырех групп курсантов. Результаты показали, что все группы курсантов характеризуются общностью базовых ценностей (здоровье, друзья, счастливая семейная жизнь), предпочитаемым мотивом выбора профессии (стать защитником Родины, семейная династия, интерес к профессии), ориентацией студентов на достижение успеха, отсутствием в социометрических структурах групп изолированных учащихся, общностью представлений о группе («дружба», «коллектив», «досуг»).

По нашему мнению, выявленное межгрупповое сходство в социальнопсихологических профилях определяется особенностями организационнообразовательной среды.

Результаты анализа выраженности суверенности психологического пространства по общей шкале и отдельным субшкалам в каждой из групп, представлены в таблице 1. 
Таблица 1.

Выраженность разных показателей суверенности психологического пространства личности в учебных группах полузакрытого типа.

\begin{tabular}{|c|c|c|c|c|c|}
\hline \multirow{2}{*}{$\begin{array}{l}\text { Субшкала суверенности } \\
\text { психологического } \\
\text { пространства }\end{array}$} & \multicolumn{4}{|c|}{ Группы } & \multirow{2}{*}{$\begin{array}{c}\text { Объединенная } \\
\text { группа }\end{array}$} \\
\hline & Группа 1 & Группа 2 & Группа 3 & Группа 4 & \\
\hline $\begin{array}{l}\text { Суверенность ффизического } \\
\text { тела }\end{array}$ & 1,33 & 1,33 & 1,45 & 1,77 & 1,46 \\
\hline Суверенность территории & 1,27 & 1,43 & 1,45 & 1,58 & 1,43 \\
\hline Суверенность вещей & 1,83 & 1,73 & 2,03 & 1,85 & 1,86 \\
\hline Суверенность привычек & 1,9 & 1,87 & 2,21 & 2,19 & 2,03 \\
\hline $\begin{array}{l}\text { Суверенность социальных } \\
\text { связей }\end{array}$ & 2,33 & 2,4 & 2,17 & 2,31 & 2,3 \\
\hline Суверенность ценностей & 2,2 & 2,23 & 2,38 & 2,46 & 2,31 \\
\hline $\begin{array}{l}\text { Суверенность } \\
\text { психологического } \\
\text { пространства }\end{array}$ & 1,3 & 1,4 & 1,52 & 1,73 & 1,49 \\
\hline
\end{tabular}

Примечание: в таблице приведены средние значения по каждой шкале.

Обнаружено, что в четырех учебных группах полузакрытого типа наблюдался уровень травматизации и депривированности суверенности, причем как по общему показателю СПП, так и по отдельным субшкалам. Выявленные нами различия в выраженности показателей не являются значимыми (по критерию Н Краскала-Уоллиса). Общий профиль СПП во всех группах совпадает. Тенденция к нормальному уровню СПП (по нормам теста) наблюдалась в сфере суверенности социальных связей (СС) и суверенности ценностей (СЦ). Здесь несущественные различия по средним значениям присутствовали лишь в третьей группе. Наиболее проблемными зонами СПП для всех четырех групп явились: "суверенность фризического тела" и «суверенность территории». Обнаруженный нами фракт вполне прогнозируемый - ограничение свободы перемещения в фризическом пространстве образовательного учреждения снижает уровень приватности по данным сфрерам. В то же время выявили, что показатели суверенности привычек различались в исследованных группах - две группы респондентов более тяжело переживали изменения в своей жизни, были не готовы отказаться от старых привычек. Также были обнаружены межгрупповые различия в выраженности показателей «суверенности вещей». Респонденты третьей группы продемонстрировали более высокий уровень суверенности по этой шкале.

Отсутствие статистически значимых различий позволило нам реализовать поставленные в работе цель и задачи по выявлению личностных и групповых 
факторов суверенности психологического пространства в обобщенной группе учащихся военного вуза. Аргументируя выбранный дизайн исследования, следует отметить направленность авторов на изучение общих закономерностей социально-психологической детерминации суверенности личности в специфичных условиях организационно-образовательной среды военного вуза.

В качестве предикторов выступили социально-психологические характеристики личности и групповые характеристики.

Результаты регрессионного анализа показали, что 80\% распределения показателей суверенности психологического пространства (обобщенный показатель СПП) зависит $(R=0,895 ; R 2=0,802 ; \quad F=47,21 ; p=0,000)$ от восприятия респондентами своей группы как группы совместного проведения досуга $(\beta=-0,176 ; t=-3,895 ; p=0,000)$. На выраженность обобщенного показателя СПП также влияют: мотив выбора профессии, которой обучают в вузе $(\beta=0,14 ; t=3,029 ; p=0,003)$, ориентация на ценность друзей $(\beta=-$ 0,099; $\mathrm{t}=-2,161 ; \mathrm{p}=0,033)$, а также понимание респондентами важности соблюдения Устава как свода законов, регулирующего поведение учащихся в вузе $(\beta=-0,132 ; t=-2,851 ; p=0,005)$. Принимая во внимание знаки переменных в модели, отметим, что низкая ориентация на ценность друзей, внутреннее непринятие Устава согласуются с тем, что группа не воспринимается личностью как сообщество друзей, с которыми можно провести досуг. При этом она ценится как группа единомышленников, поскольку все ее члены разделяют мотивы выбора профессии, которой обучают в вузе. Причем вклад в модель последнего из перечисленных предикторов больше, чем других. По всей видимости, такая личностная позиция, отличающаяся дистанцированностью, позволяет курсантам поддерживать суверенность своего психологического пространства в организационно-образовательной среде военного вуза.

Предикторами суверенности фризического тела (CФT) (R=0,751; R2= 0,564; $F=23,279 ; p=0,000)$ стали: представления о группе в рамках совместного досуга $(\beta=0,2 ; t=2,944 ; p=0,004)$, показатель групповой сплоченности $(\beta=$ $0,209 ; t=3,177 ; p=0,002)$, мотив не продолжать в будущем военную карьеру $(\beta=0,208 ; t=3,157 ; p=0,002)$ и мотив поступления в вуз, связанный с интересом к выбранной профессии $(\beta=0,143 ; t=1,19 ; p=0,031)$. Стоит отметить, что в этой модели фракторов максимальный вклад привносит групповая характеристика, а не личностная. Интерпретируя результат, отметим, что все связи в модели положительные. Следовательно, респонденты с высокими показателями по шкале СФТ воспринимают свою группу в большей степени, как группу студентов, с которыми приятно пообщаться пока учишься, чем как группу курсантов военного вуза, ориентированных на профессиональную карьеру военного. 
Сохранение суверенности территории (СТ) в полузакрытой группе наиболее проблемная зона суверенности психологического пространства курсантов. В регрессионной модели СТ $(\mathrm{R}=0,825 ; \mathrm{R} 2=0,681 ; \mathrm{F}=24,943$; $\mathrm{p}=0,000)$ в качестве ее предикторов выступили: мотив интереса к профессии при поступлении в вуз $(\beta=0,229 ; t=3,907 ; p=0,000)$, представления о группе как о товарищах $(\beta=0,141 ; t=2,395 ; p=0,018)$, ориентация на ценность активной, деятельной жизни ( $\beta=0,187 ; \mathrm{t}=3,067 ; \mathrm{p}=0,003)$, мотив выбора гражданской профрессии в будущем (адвокат, бизнесмен) $(\beta=0,141 ; t=3,05 ; p$ $=0,003)$. Все с положительным знаком. С отрицательным знаком в модель вошла ориентация на ценность свободы как независимости в поступках и действиях $(\beta=-0,146 ; \mathrm{t}=-2,453 ; \mathrm{p}=0,016)$. Следовательно, на восприятие безопасности фризического пространства оказывают влияние ориентация на ценность активной жизни, построение образа будущего, не связанного с военной профессией. В таком случае группа воспринимается как группа товарищей, но свобода личности как ценность здесь малозначима. Вероятно, это связано с интернатным проживанием курсантов, которое стимулирует активное взаимное содействие членов группы, общее подчинение правилам организационно-образовательной среды, что и обеспечивает им чувство безопасности.

Обобщая результаты анализа, отметим, что социально-психологические характеристики личности в целом вносят больший вклад в показатели суверенности психологического пространства, чем групповые характеристики. Выявленный факт объясняется следующим. Во-первых, тем, что сам феномен СПП личности является личностной характеристикой, формируется в течение всей жизни, посредством взаимодействия с социальной средой. На первом этапе вхождения личности в учебную группу полузакрытого типа процесс ее адаптации протекает посредством разрешения конфликта «личность - группаорганизационно-образовательная среда». Под влиянием групповых норм и требований организационно-образовательной среды происходит изменение уровня СПП личности, сорормированного к моменту поступления в вуз.

\section{Выводы.}

1. В исследованных учебных группах полузакрытого типа выраженность показателей суверенности психологического пространства личности в целом указывает на травматизацию и депривированность учащихся военного вуза.

2. Сохранение сорормированной суверенности личности в условиях жизнедеятельности в группе полузакрытого типа обусловлено, с одной стороны, социально-психологическими характеристиками личности - внутренней мотивацией обучения в вузе, представлениями об учебной группе как референтной, ориентациями на ценности социальной жизни. С другой стороны, психологическая суверенность личности зависит от уровня групповой 
сплоченности, социометрического статуса члена группы, степени принятия личностью групповых норм. Вклад личностных характеристик в выраженность суверенности психологического пространства больше, чем групповых.

3. Наиболее проблемными зонами сохранения суверенности психологического пространства личности в полузакрытой группе учащихся военного вуза являются суверенность фризического тела и суверенность территории.

4. Поддержанию суверенности фризического тела и территории способствуют сплоченность учебной группы, интерес курсантов к будущей профессии, их ориентации на ценность активной жизни и построение образа будущего с гражданской профессией.

Заключение. В развитии работы предполагается продолжить анализ в направлении исследования предикторов суверенности психологического пространства личности в разных учебных группах полузакрытого и открытого типа. Также важным является анализ влияния суверенности психологического пространства личности на групповые феномены, к примеру, групповую рефлексивность. Поставленные на перспективу задачи связаны с поиском специфики свойств коллективного субъекта в условиях учебной полузакрытой группы.

\section{Литература}

1. Додова Л.М., Константиниди Л.Ю. Роль образовательной среды в личностно-психологическом становлении воспитанников кадетского корпуса // Евразийский Союз Учёных. 2015. № 6-6 (15). с. 54-56.

2. Дробышева Т.В., Тарасов С.В., Сахарова Е.Ю. Межличностные отношения подростков в разных условиях социализации (на примере кадетов и учащихся общеобразовательной школы) // Институт психологии Российской академии наук. Социальная и экономическая психология. 2018. Т. 3. № 4 (12). с. 108-127.

URL:http://soc-econom-psychology.ru/cntnt/bloks/dopmenu/archive/n2018/t3-4/s18-04-06.html

3. Нартова-Бочавер С.K. Психологическое пространство личности: монография. М.: Прометей, 2005. 310 с.

4. Нартова-Бочавер С.K. Новая версия опросника «Суверенность психологического пространства - 2010» // Психологический журнал. 2014. Т.35. №3. с. 105-119.

5. Тарасов С.В., Дробышева Т.В. Полузакрытая группа как объект социально-психологического исследования: критерии и некоторые признаки//Социальная психология: вопросы теории и практики. Материалы VI Международной научно-практической конференции памяти М.Ю. Кондратьева «Социальная психология: вопросы теории и 
практики» (12-13 мая 2021 г.). М.: ФГБОУ ВО МГППУ, 2021. с. 544-546 URL: https://psyjournals.ru/socpsy_qtp_2021.

6. Тарасов С.В., Дробышева Т.В. Связь межличностных отношений и ценностных ориентаций подростков в полузакрытой учебной группе //Актуальная психология. Научный вестник. -Ереван, 2019. № 2 (4). с. 268-274. URL: http://psyarm.com/?page_id=623

7. Фанталова Е.Б. Диагностика и психотерапия внутреннего конфрликта, Самара: Издательский дом «БАХРАХ-М», 2001. 128 с.

8. Фетискин Н.П. Социально-психологическая диагностика развития личности и малых групп: учеб. пособие / Н.П. Фетискин, В.В. Козлов, Г. М.Мануйлов. М.: Изд-во Института психотерапии, 2002. 188 с.

9. Чернышев А.С., Сарычев С.В. Социально-психологическая модель учебной группы как субъекта жизнедеятельности//Ученые записки. Электронный научный журнал Курского государственного

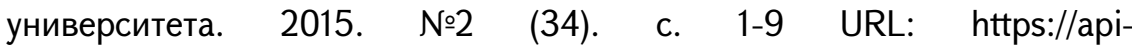
mag.kursksu.ru/api/v1/get_pdf/1704.

\section{THE SOVEREIGNTY OF THE INDIVIDUAL PSYCHOLOGICAL SPACE IN SEMI- CLOSED LEARNING GROUP: PERSONAL AND GROUP FACTORS}

The study has been executed as part of state assignment No. 0138-2021-0010 Tarasov S.V., Drobysheva T.V. (Institute of Psychology RAS, Moscow, Russia)

The study examines the preservation of the psychological privacy of individuals in a semi-closed group as an indicator of their subjective qualities. The aim of the research was to identify the contribution of socio-psychological characteristics (personal and group) to the regression model of the sovereignty of psychological space in the group of students of military higher education. The results showed that the sovereignty of psychological space is due more to socio-psychological (values, motivation to enter and choose a profession in the future, perceptions of a group) than to group (group cohesion, sociometric status, group norms) characteristics.

Keywords: sovereignty of the individual psychological space, semi-closed learning group, relationship between individual and collective subject, specifics of socialization. 